\title{
Original
}

\section{A pilot study on assessment of locomotor behavior using a video tracking system in minipigs}

\author{
Jincheol SEO ${ }^{1,2) *}$, Hyeon-Gu YEO ${ }^{1,3) *}$, Junghyung PARK ${ }^{1)}$, Jinyoung $\mathrm{WON}^{1)}$, Keonwoo $\mathrm{KIM}^{1,4)}$, \\ Yeung Bae JIN ${ }^{1)}$, Bon-Sang KOO ${ }^{1)}$, Kyung Seob LIM ${ }^{5)}$, Kang-Jin JEONG ${ }^{1)}$, Philyong KANG ${ }^{5)}$, \\ Hwal-Yong LEE ${ }^{1)}$, Hee-Chang SON ${ }^{5}$, Seung Ho BAEK ${ }^{1)}$, Chang-Yeop JEON ${ }^{1)}$, Bong-Seok SONG ${ }^{5}$, \\ Jae-Won HUH ${ }^{1,3)}$, Dong-Seok LEE ${ }^{2)}$, Sang-Rae LEE ${ }^{1,3)}$, Sun-Uk KIM ${ }^{3,5)}$ and Youngjeon LEE ${ }^{1,3}$ ) \\ 1)National Primate Research Center, Korea Research Institute of Bioscience and Biotechnology (KRIBB), 30 Yeongudanji-ro, \\ Ochang-eup, Cheongwon-gu, Cheongju, Chungbuk 28116, Republic of Korea \\ ${ }^{2)}$ School of Life Sciences, BK21 Plus KNU Creative BioResearch Group, Kyungpook National University, 80 Daehak-ro, \\ Buk-gu, Daegu 41566, Republic of Korea \\ 3) Department of Functional Genomics, KRIBB School of Bioscience, Korea University of Science and Technology, 217 \\ Gajeong-ro, Yuseong-gu, Daejeon 34113, Republic of Korea \\ 4) Department of Physical Therapy, Graduate School of Inje University, 197 Inje-ro, Gimhae, Gyeongnam 50834, Republic of \\ Korea \\ 5) Futuristic Animal Resource \& Research Center, KRIBB, 30 Yeongudanji-ro, Ochang-eup, Cheongwon-gu, Cheongju, \\ Chungbuk 28116, Republic of Korea
}

\begin{abstract}
Pigs are often selected for large animal models including for neuroscience and behavioral research, because their anatomy and biochemistry are similar to those of humans. However, behavioral assessments, in combination with objective long-term monitoring, is difficult. In this study, we introduced an automated video tracking system which was previously used in rodent studies, for use with pig models. Locomotor behaviors (total distance, number of zone transitions, and velocity) were evaluated and their changes were validated by different 1-methyl4-phenyl-1,2,3,6-tetrahydropyridine (MPTP) administration methods and dosing regimens. Three minipigs (23-29 $\mathrm{kg}$ ) received subcutaneous or intravenous MPTP, either 1 or 3 times per week. Immediately after MPTP injection, the minipigs remained in a corner and exhibited reduced trajectory. In addition, the total distance travelled, number of zone transitions, and velocity were greatly reduced at every MPTP administration in all the minipigs, accompanying to increased resting time. However, the MPTP-induced symptoms were reversed when MPTP administration was terminated. In conclusion, this automated video-tracking system was able to monitor long-term locomotor activity and differentiate detailed alterations in large animals. It has the advantages of being easy to use, higher resolution, less effort, and more delicate tracking. Additionally, as our method can be applied to the animals' home pen, no habituation is needed.
\end{abstract}

Key words: 1-methyl-4-phenyl-1,2,3,6-tetrahydropyridine (MPTP), behavior, locomotor, minipig, video tracking

\section{Introduction}

Minipigs (Sus scrofa) are considered a suitable animal species for modeling human diseases, because they are more similar to humans in anatomy, physiology, and biochemistry than rodents [7-9, 13, 17, 19, 21]. Additionally, the pig brain is largely compatible with the human brain when using imaging modalities such as MRI and PET-CT to identify structural and functional changes. Furthermore, advanced cognition and the capacity

(Received 17 May 2019 / Accepted 2 August 2019 / Published online in J-STAGE 3 September 2019)

Corresponding authors: S.-U.Kim.e-mail:sunuk@kribb.re.kr,Y.Lee.e-mail:neurosci@kribb.re.kr

*These authors contributed equally to this work.

Supplementary Figures: refer to J-STAGE: https://www.jstage.jst.go.jp/browse/expanim

(c) (1) $(-)$ This is an open-access article distributed under the terms of the Creative Commons Attribution Non-Commercial No Derivatives BY NG ND (by-nc-nd) License <http://creativecommons.org/licenses/by-nc-nd/4.0/>.

(C2020 Japanese Association for Laboratory Animal Science 
for complex behaviors enable translational behavioral research using pig models [13]. Moreover, in comparison with non-human primates such as monkeys, pigs have considerable advantages related to political, ethical, and economic issues; additionally, homogeneous inbred laboratory breeds are available, and housing and handling are relatively easy $[12,17]$.

Since the relationship between 1-methyl-4-phenyl1,2,3,6-tetrahydropyridine (MPTP) and human parkinsonism became evident $[4,14]$, MPTP has been widely used to induce animal models of Parkinson's disease in diverse species such as rodents, cats, monkeys, and pigs [7-9, 19, 21, 25]. Systemic administration of MPTP, which is metabolized to 1-methyl-4-phenylpyridinium ion (MPP+) by monoamine oxidase B, selectively damages the nigrostriatal dopaminergic neurons responsible for movement control [4, 15, 16].

Previous studies using minipigs to model MPTP-induced parkinsonism have revealed the impairment of nigrostriatal dopamine pathway by biochemical, histological, and PET imaging analyses [7-9, 19, 21]. Furthermore, these studies demonstrated parkinsonian symptoms based on qualitative behavioral observations or manually scored rating scales [7-9, 19, 21]. However, to measure the behavioral alterations of an MPTPinduced Parkinson's disease minipig model, it is necessary to quantify behavioral parameters more objectively, accurately, and reliably. In the present study, we used an automated video-based tracking system that was developed for behavioral quantification in rodents $[1,5,26]$, which enables long-term follow-up and prevents the observer error or subjective rating.

Several MPTP administration methods and dosing regimens have been investigated in species such as rodents and primates, with the aim of discovering the best model of human parkinsonism [2, 28]. For example, in nonhuman primates, the severity of parkinsonism varies depending on the route, dose, and frequency of MPTP administration [11]. Therefore, long-term monitoring is important, and MPTP administration methods and dosing regimens should be modified by species, body weight, and age in order to accurately model parkinsonian symptoms. This necessity is evident from findings that some strains of mice are resistant to MPTP-induced parkinsonism $[20,28]$.

In this pilot study, we aimed to quantify the locomotor behavior in minipigs, using an automated video-based tracking system. We also validated its sensitivity to detect changes in varied MPTP administration strategies.

\section{Materials and Methods}

\section{Experimental animals}

We studied mature male KSP minipigs $(n=3)$ developed by Futuristic Animal Resource \& Research Center (FARRC) [29], that were 14-18 months of age and weighed between 23-29 kg (Table 1, Supplementary Fig. 1A). The minipigs were maintained in indoor stainless pens at the FARRC under controlled environmental conditions including temperature of $21 \pm 2{ }^{\circ} \mathrm{C}$, a relative humidity of $50 \pm 5 \%$, a light intensity of 300 lux, ventilation at 10-20 times per $\mathrm{h}$. The minipigs were fed a commercial pellet intended for laboratory pigs (Purina \#238075, Cargill, Dangjin, Korea) with supplemented of vitamins, amino acid and minerals. Probiotics and prebiotics therapy were also performed for all animals. In pens, there were hanging chains and balls for improved environmental enrichments. Animal health including virus and bacterial infections were periodically monitored and managed by swine veterinary experts. Experiment were performed in accordance with the Guide for the care and use of laboratory Animals published by the National Institutes of Health. All procedures were approved by the KRIBB Institutional animal care and use committee (Approval No. KRIBBAEC-15122).

\section{MPTP administration}

MPTP (1 mg/kg; Sigma-Aldrich, St. Louis, MO, USA) was dissolved in saline to a final concentration of $10 \mathrm{mg} /$ $\mathrm{ml}$ and injected subcutaneously (SC) between the left and right tits or intravenously (IV) in an ear vein, based on previous studies of minipigs [7-9, 19] (Supplementary Figs. 1C and D). The experimental design for MPTP administration is outlined in Table 1.

Table 1. The minipigs and experimental design in this study

\begin{tabular}{cccccccccc}
\hline Label & ID & Sex & $\begin{array}{c}\text { BW } \\
(\mathrm{kg})\end{array}$ & $\begin{array}{c}\text { Age } \\
(\text { months })\end{array}$ & $\begin{array}{c}\text { Injection } \\
\text { route }\end{array}$ & $\begin{array}{c}\text { Dose } \\
(\mathrm{mg} / \mathrm{kg})\end{array}$ & $\begin{array}{c}\text { Injection } \\
\text { times }\end{array}$ & $\begin{array}{c}\text { Injection } \\
\text { period }\end{array}$ & $\begin{array}{c}\text { Total dose } \\
(\mathrm{mg} / \mathrm{kg})\end{array}$ \\
\hline G1 & $1-3-006$ & male & 29 & 18 & $\mathrm{SC}$ & 1 & $3 /$ week & 7 weeks & 21 \\
$\mathrm{G} 2$ & $3-3-018$ & male & 27 & 18 & $\mathrm{SC}$ & 1 & $1 /$ week & 3 weeks & 3 \\
G3 & $3-4-001$ & male & 23 & 14 & IV & 1 & $1 /$ week & 4 weeks & 4 \\
\hline
\end{tabular}

ID, identification; BW, body weight; SC, subcutaneously; IV, intravenously. 
Measurement of locomotion using a video-tracking system

Each minipig was placed in an open-field testing arena $(2.2 \mathrm{~m} \times 3.2 \mathrm{~m})$ in a room equipped with a $\mathrm{CCD}$ camera positioned at the center of the ceiling. The camera was connected to a computer in another room (Supplementary Fig. 1B). Locomotion was measured by a computerized video tracking system (SMART 3.0, Panlab SL, Barcelona, Spain) that is commonly used in rodent studies $[6,26]$. The minipigs were habituated to the testing environment over a period of 2 weeks and had $30 \mathrm{~min}$ to acclimate to the testing arena on the day of testing. Testing took place between 13:00-17:00, in order to avoid mealtime. Trials were performed in 60 min, with video recording and measurement occurring after configurations such as the contrast and threshold value recordings. The baseline recordings consisted of a trial every 2-3 days, for 2 weeks after habituation was completed, and the data from these trials were averaged. During the period of MPTP administration, testing consisted of 3 consecutive trials: before $0-1 \mathrm{~h}$, after $0-1 \mathrm{~h}$, and after 1-2 $\mathrm{h}$. The arena floor was washed with tap water and swept after each minipig completed testing. The testing arena was digitally divided into 12 equal zones (Supplementary Fig. 1B and Fig. 1). Further data analyses were conducted using the middle $45 \mathrm{~min}$ recording section from each trial. Five categories of behavior were measured: trajectory of ambulation, total distance $(\mathrm{cm})$, number of zone transitions (the number of zones in which the minipig's center of mass entered), velocity $(\mathrm{cm} / \mathrm{s})$, and the ratio of immobile (resting) duration to slow and fast moving duration (resting $<0.1 \mathrm{~cm} / \mathrm{s}$, slow $0.1-10 \mathrm{~cm} / \mathrm{s}$, fast $>10 \mathrm{~cm} / \mathrm{s}$ ). The threshold was configured based on the minipig's moving speed pattern. To minimize tracking errors, anti-vibration and artifact rejection filters were applied, thereby producing minimal variation in the center of mass.

\section{Results}

Acute effects of MPTP on spontaneous ambulation

The acute effects of MPTP on spontaneous ambulation were evaluated using trajectory data. In all 3 different administration methods, ambulation decreased immediately after MPTP injection $(0-1 \mathrm{~h})$. This decrease was more prominent with IV administration compared to SC administration (Fig. 1). However, trajectory values were low in all minipigs $1-2 \mathrm{~h}$ following MPTP administration. During this period, the peaks of the 3D graphs demonstrate that the minipigs typically remained in a corner of the arena (Fig. 1) and exhibited reduced locomotor activity (Fig. 2D). Furthermore, all minipigs had an abnormally flexed posture with bent heads and hind limbs (Fig. 2B), although normal posture with elevated heads (Fig. 2A) and typical locomotor activity (Fig. 2C) was observed before MPTP administration.

Subacute effects of MPTP on the total distance travelled, number of zone transitions, velocity, and the ratio of movement speeds

In order to further assess locomotor behavior during 3 different MPTP administration protocols, the total distance travelled, number of zone transitions, velocity, and the ratio of movement speeds (resting, slow, fast) were measured. The total distance travelled, number of zone transitions, and velocity were greatly reduced at every MPTP administration in all the minipigs. The average total distance travelled was reduced by $74 \%$ (range $65-94 \%$ ) in G1, 75\% (range 53-91\%) in G2, and 89\% (range $74-100 \%$ ) in G3, compared to their respective baseline (Fig. 3A). The mean total number of zone transitions was reduced by $77 \%$ (range $64-94 \%$ ) in G1, 78\% (range $57-92 \%$ ) in $\mathrm{G} 2$, and $89 \%$ (range $74-100 \%$ ) in G3, compared to their respective baseline (Fig. 3B). The velocity was reduced by $74 \%$ (range $65-94 \%$ ) in G1, $75 \%$ (range $53-91 \%$ ) in $\mathrm{G} 2$, and $89 \%$ (range $74-100 \%$ ) in G3, compared to their respective h baseline (Fig. 3C). However, the minipigs had fully recovered at 2 weeks (G2, G3) or 4 weeks (G1) after the last MPTP administration. In addition, the graph patterns for the 3 parameters differed only in scale (Fig. 3), indicating that the values are correlated with each other.

All minipigs exhibited basal global activity with an average of $68 \%$ resting time, $16 \%$ slow locomotion, and $16 \%$ fast locomotion at baseline (Fig. 4). However, the duration of resting time during MPTP administration (G1: week 1-7, G2: week 1-3, G3: week 1-4) considerably increased in all minipigs compared to their individual baseline. During the MPTP administration period, an average of $93 \%$ of time was resting (range $89-100 \%$ ) in G1, 91\% (range 81-97\%) of time in G2 was resting, and $97 \%$ (range $93-100 \%$ ) of time in G3 was resting (Fig. 4). Similar to the results for the total distance travelled, number of zone transitions, velocity (Fig. 3), the minipigs had recovered at 2 weeks (G2, G3) or 4 weeks (G1) after the last MPTP administration (Fig. 4).

\section{Physical examination}

Locomotor dysfunction can impede food intake. Therefore, we measured the body weight (Supplementary Fig. 2A), which increased constantly (Supplementary Fig. 2B). There were no serious physical side effects based on the body weight and visual inspection. 

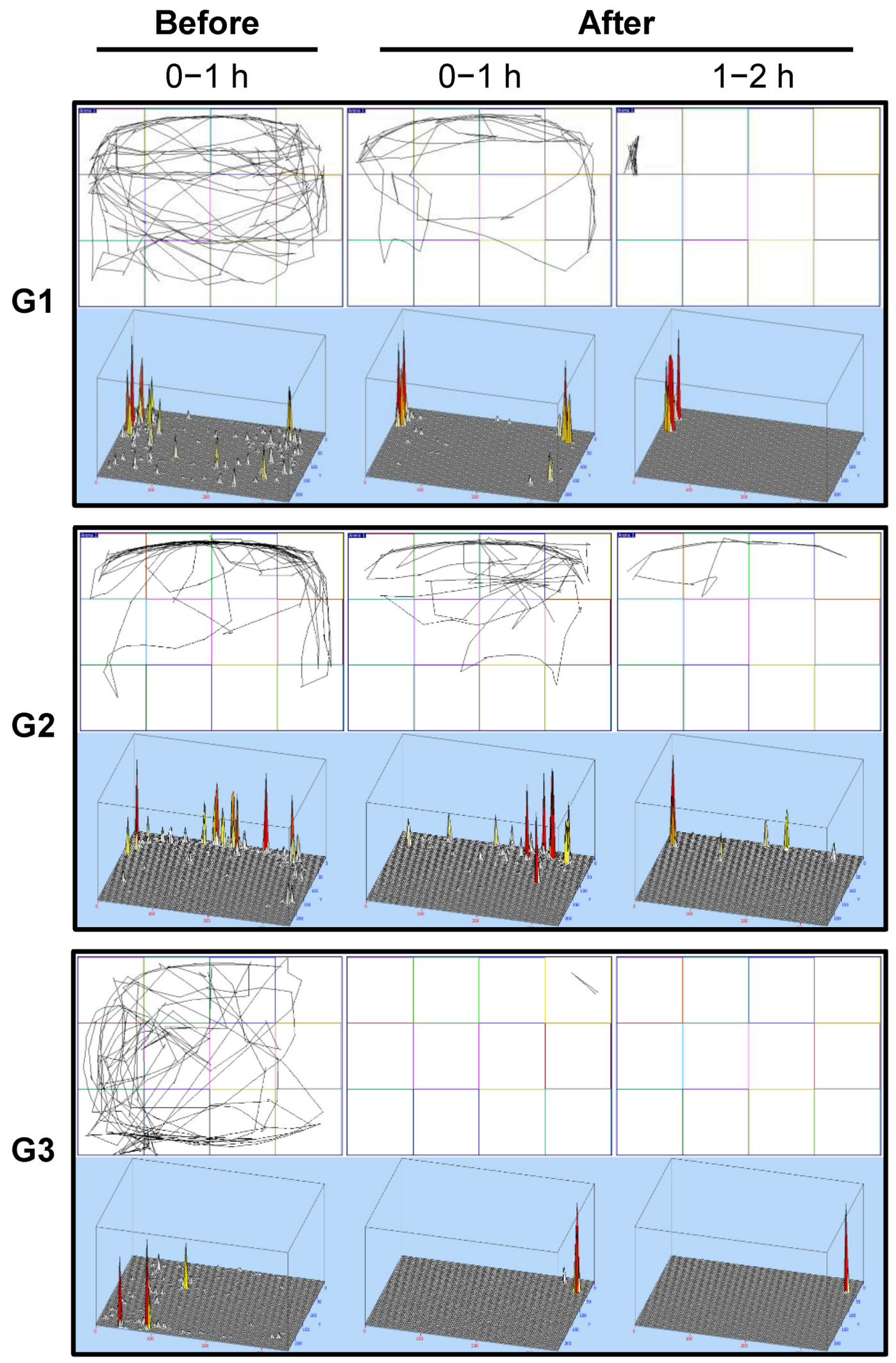

Fig. 1. Acute effects of 1-methyl-4-phenyl-1,2,3,6-tetrahydropyridine (MPTP) on spontaneous ambulation during 3 different administration protocols in minipigs. MPTP $(1 \mathrm{mg} / \mathrm{kg})$ was administered subcutaneously 3 times per week (top), once per week (middle), and intravenously once per week (bottom). The test arena was divided into 12 equal zones. The trajectory was tracked for a $45 \mathrm{~min}$ period during the middle of each 60 min trial (upper: 2D, lower: $3 \mathrm{D}$, in each panel). Three consecutive trials were conducted: before $0-1 \mathrm{~h}$, after $0-12 \mathrm{~h}$, and after $1-2 \mathrm{~h}$ of MPTP administration (left to right in each panel). 
Before
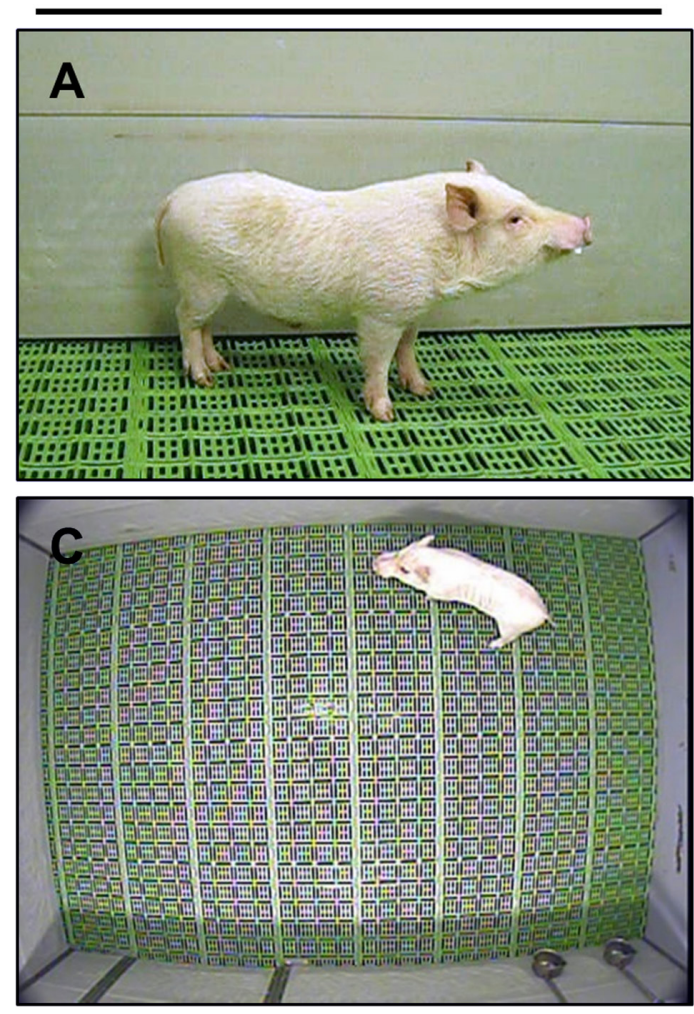

After
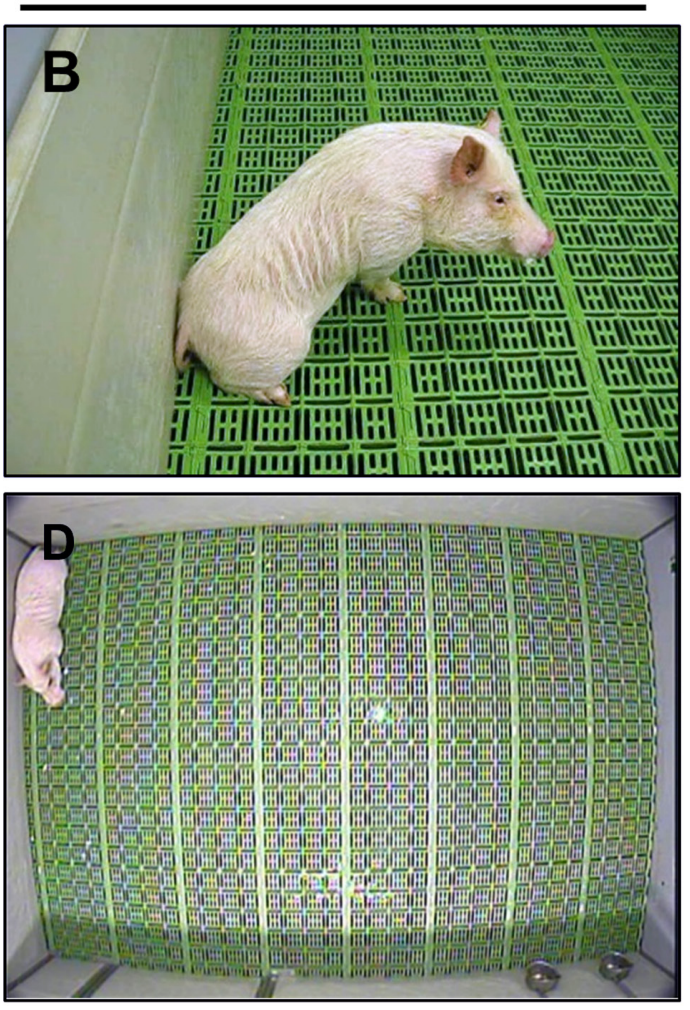

Fig. 2. Representative images to show normal posture standing straight with elevated head, and normal locomotor activity with movement around the test arena (A, C). Flexed posture with bent head and hind limbs, and reduced locomotor activity while remaining in a corner of the test arena $1-2 \mathrm{~h}$ following MPTP administration in the G3 minipig (B, D).

\section{Discussion}

This is a report to quantify alterations of locomotor behavior induced by MPTP administration in minipigs, using an automated video-tracking system. The videotracking system was developed in rodent studies $[1,5$, 26], but it was successfully used in the present study in minipigs. As shown in Fig. 3, the total distance, number of zone transitions, and velocity were decreased by MPTP administration and increased when it was stopped, suggesting a correlation between these parameters. Additionally, it provides evidence that changes in the total distance arise from zone transition and speed. Furthermore, because the changes in the total distance do not always follow the change of the zone transition and speed in the same way, it is necessary to examine these parameters simultaneously.

Numerous MPTP administration protocols and behavioral assessments by scoring with rating scales in minipigs have been reported for modeling Parkinson's disease $[8,9,19,21]$. However, raters may become tired and error-prone, or make subjective assessments. Although recent studies have proposed novel tools for quantifying the locomotor activity of minipigs $[10,18]$, these tools are difficult to access, and there is need for additional tools. This automated video-tracking system in our study also works well for large animals and has the advantages of being easy to use, higher resolution, less effort, and more delicate tracking. Additionally, as our method can be applied to the animals' home pen, no habituation is needed. The recent study showed that implantation of the telemetry device has enabled physiological signals to be monitored without side effects [30]. Future studies that combines an automated video-tracking system with a telemetry monitoring system would be useful to assess behavior and physiology comprehensively.

Characterization and validation of the MPTP-induced animal models for Parkinson's disease have been ongoing for the past 2 decades, and still requires further research $[24,27]$. Therefore, it is necessary to attempt several protocols, including variations in doses, delivery routes, and injection schedules. The refined model can then be used to test the efficacy of potential treatments. In the present study, we advanced behavioral evaluation, using an automated video-based tracking system to assess and monitor locomotor activity in 3 different variations of the MPTP model. Furthermore, we verified that the 3 MPTP-treated minipigs consistently demonstrated 
A
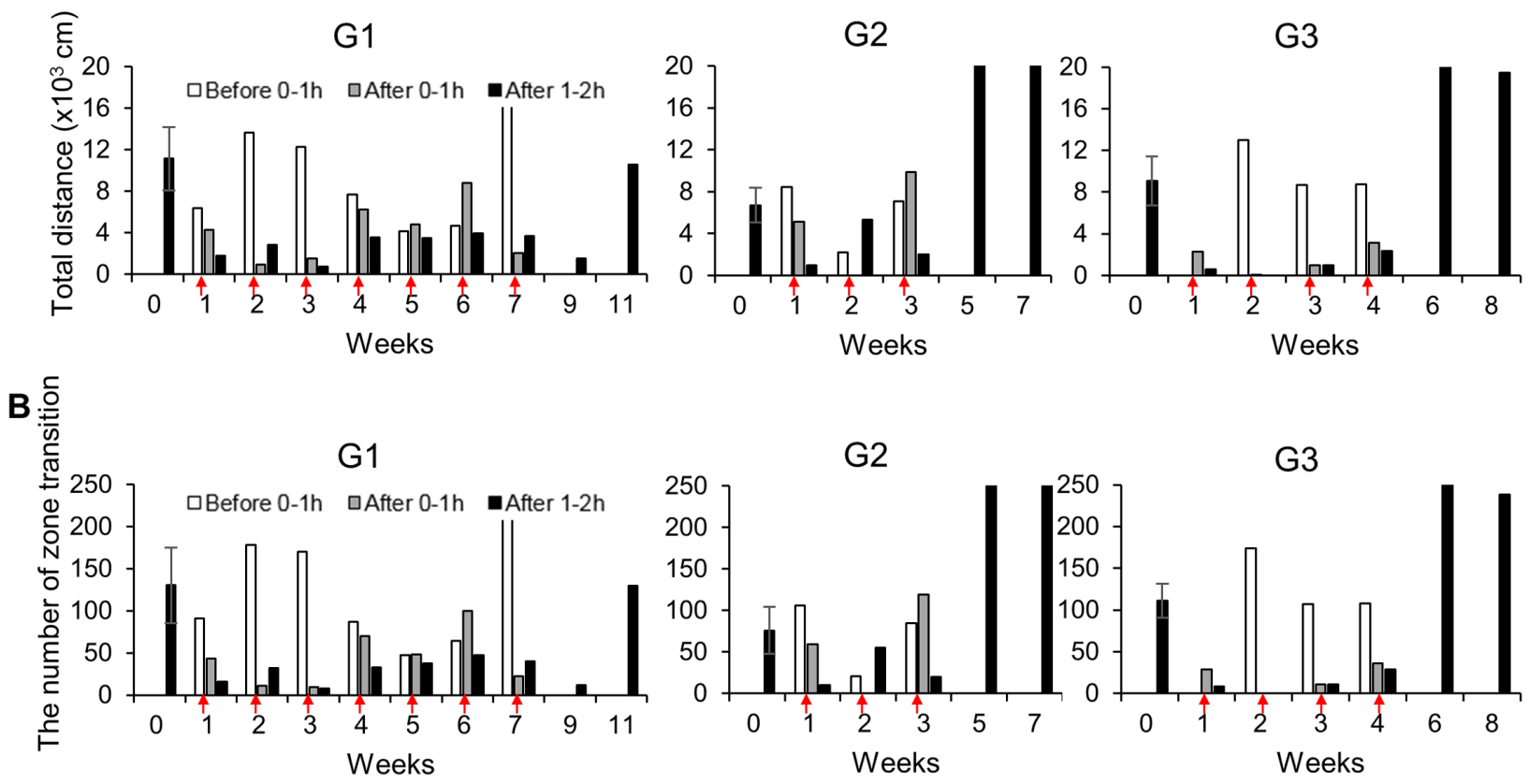

C
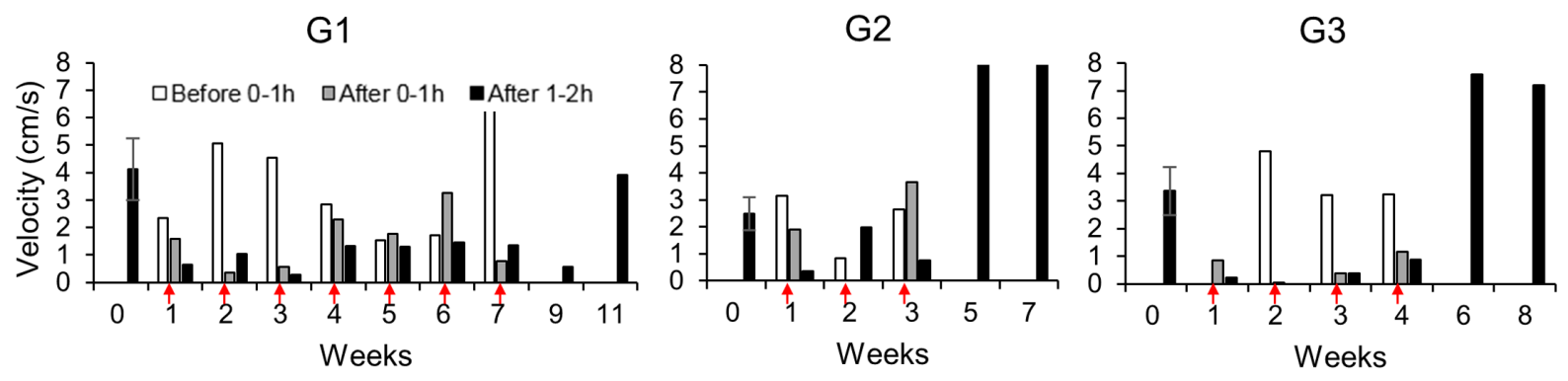

Fig. 3. Subacute effects of 1-methyl-4-phenyl-1,2,3,6-tetrahydropyridine (MPTP) on the total distance travelled, number of zone transitions, and velocity following 3 different administration protocols in minipigs. The total distance traveled (A), number of zone transitions (B), and velocity (C) were measured in a $45 \mathrm{~min}$ period for the baseline (mean $\pm \mathrm{SD}$ ), before $0-1 \mathrm{~h}$, after $0-1 \mathrm{~h}$, and after 1-2 h of MPTP administration. MPTP $(1 \mathrm{mg} / \mathrm{kg})$ was administered subcutaneously 3 times per week in G1, once per week in G2, and once per week through the intravenous route in G3 (arrows). The test arena was divided into 12 equal zones.

\section{G1}

G2

G3
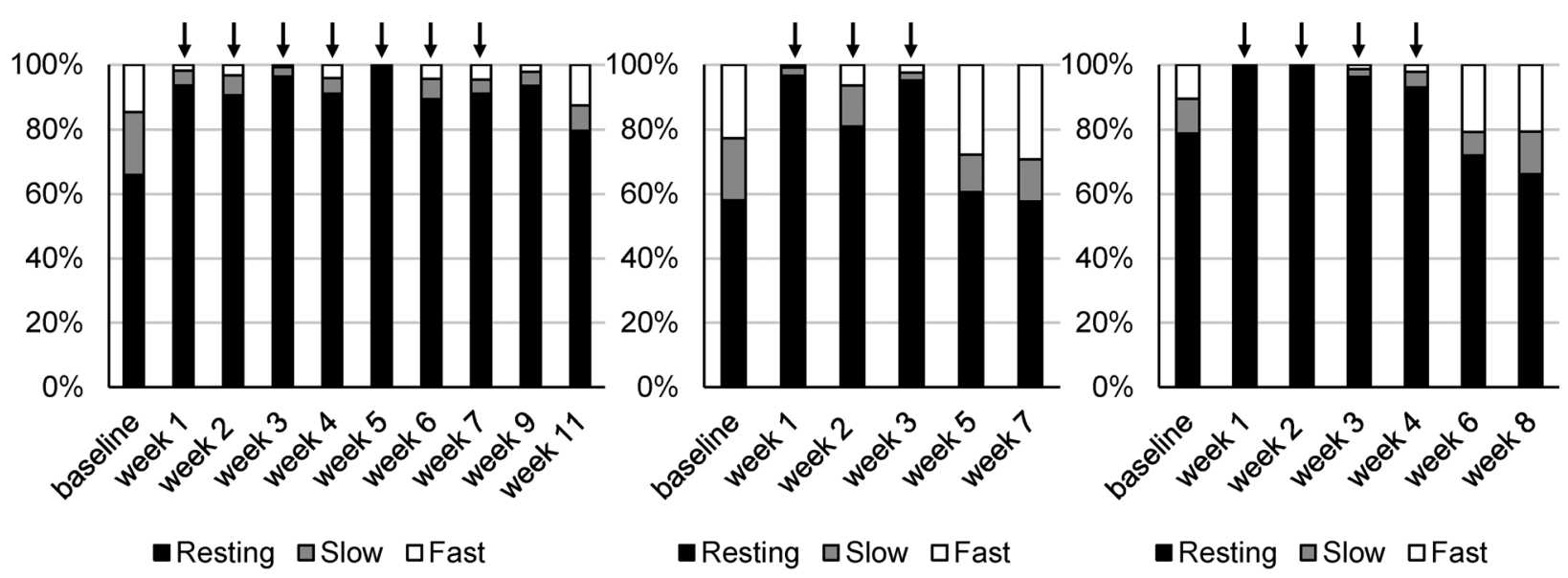

Fig. 4. Subacute effects of 1-methyl-4-phenyl-1,2,3,6-tetrahydropyridine (MPTP) on the ratio of movement speeds following 3 different administration protocols in minipigs. The proportion of locomotor behavior (resting, slow, fast) was calculated for a $45 \mathrm{~min}$ period before (baseline) and $2 \mathrm{~h}$ following MPTP administration. MPTP $(1 \mathrm{mg} / \mathrm{kg})$ was administered subcutaneously 3 times each week in G1, once per week in G2, and intravenously once per week in G3 (arrows). 
alterations in locomotor behavior, including trajectory, total distance, number of zone transitions, and mean locomotor speed on the day of administration. The primary symptoms of locomotor dysfunction on the day of MPTP administration were clearly demonstrated. Parkinsonian motor syndrome occurs with the death of $50 \%$ or more of dopaminergic neurons in the substantia nigra pars compacta, which projects to the striatum. This neuronal loss produces at least an $80 \%$ dopamine reduction in primates and minipigs [11, 19], suggesting that dopaminergic cell loss is not enough to induce stable behavioral alterations in this study. Indeed, we conducted in vivo PET imaging for dopamine transporter using $18 \mathrm{~F}$ FP-CIT tracer, and found no differences between the groups (data not shown). In order to consistently induce locomotor dysfunction, more than $21 \mathrm{mg} / \mathrm{kg}$ of MPTP with over 21 administrations may be required when MPTP is administered 3 days per week by SC injections. Additionally, compared to the less frequently administered SC injection protocol in G2 and the IV protocol in G3, only G1 maintained reduced locomotor activity until 2 weeks after MPTP administration ended (Figs. 3 and 4), suggesting that repeated injections are essential regardless of whether the administration is by an SC or IV route. Furthermore, SC delivery is simpler and more practical because it is not necessary to find a blood vessel, restraint handling is easier, and it is less stressful to the animal. Therefore, systemic MPTP administration by repeated SC injection, with locomotor behavior monitored by an automated tracking system is feasible for minipig Parkinson's disease modeling.

There are several possible mechanisms for behavioral recovery after MPTP administration ended. First, relatively minor damage to the nigrostriatal pathway may be compensated for by the hypersensitivity of dopamine receptors, increased dopamine release by surviving cells, and other types of adaptive plasticity [11]. Additionally, recent studies of MPTP-induced monkey models of Parkinson's disease demonstrated the spontaneous behavioral recovery by compensation mechanisms such as striatal dopaminergic neurotransmission, increased expression of dopamine transporter and tyrosine hydroxylase in the dorsal striatum, and reinforcement of serotoninergic fibers $[3,22,23]$. These results suggest that behavioral recovery in our minipig model may occur via similar compensatory mechanisms.

Although MPTP-induced animal models have been widely used for Parkinson's disease, the high rates of symptomatic variation are problematic in large animals such as monkeys and pigs [21, 24]; thus, it may be fatal to some and recoverable in others. Moreover, there are compensatory recovery mechanisms such as the sero- tonin pathway and other types of adaptive plasticity, as explained above. Therefore, it is difficult to establish an MPTP-induced stable Parkinson's disease model in large animals, which might require adjustments of MPTP administration according to the severity of behavioral symptoms. In this context, our present study suggests that automatic quantification of locomotion could be a useful tool to guide adjustments of MPTP treatment for better modeling, despite its limitation of not using a better-established MPTP model. Recently, we verified the individual adjustments of MPTP administration based on the results of the automatic quantification of global activity using this video-based tracking system developed stable chronic Parkinson's disease in monkeys [27]. Therefore, we believe that assessment of locomotor behavior using our automated video tracking system may offer an effective approach for studies using large animals.

\section{Acknowledgments}

This research was supported by grants from the Korea research institute of bioscience and biotechnology (KRIBB) research initiative program (KGM4251913, KGM4621922).

\section{References}

1. Acharjee, S., Nayani, N., Tsutsui, M., Hill, M.N., Ousman, S.S. and Pittman, Q.J. 2013. Altered cognitive-emotional behavior in early experimental autoimmune encephalitis-cytokine and hormonal correlates. Brain Behav. Immun. 33: 164-172. [Medline] [CrossRef]

2. Blandini, F. and Armentero, M.T. 2012. Animal models of Parkinson's disease. FEBS J. 279: 1156-1166. [Medline] [CrossRef]

3. Boulet, S., Mounayar, S., Poupard, A., Bertrand, A., Jan, C., Pessiglione, M., Hirsch, E.C., Feuerstein, C., François, C., Féger, J., Savasta, M. and Tremblay, L. 2008. Behavioral recovery in MPTP-treated monkeys: neurochemical mechanisms studied by intrastriatal microdialysis. J. Neurosci. 28: 9575-9584. [Medline] [CrossRef]

4. Burns, R.S., LeWitt, P.A., Ebert, M.H., Pakkenberg, H. and Kopin, I.J. 1985. The clinical syndrome of striatal dopamine deficiency. Parkinsonism induced by 1-methyl-4-phenyl1,2,3,6-tetrahydropyridine (MPTP). N. Engl. J. Med. 312: 1418-1421. [Medline] [CrossRef]

5. Chen, Y., Liang, Z., Blanchard, J., Dai, C.L., Sun, S., Lee, M.H., Grundke-Iqbal, I., Iqbal, K., Liu, F. and Gong, C.X. 2013. A non-transgenic mouse model (icv-STZ mouse) of Alzheimer's disease: similarities to and differences from the transgenic model (3xTg-AD mouse). Mol. Neurobiol. 47: 711-725. [Medline] [CrossRef]

6. Chen, Y., Liang, Z., Tian, Z., Blanchard, J., Dai, C.L., Chalbot, S., Iqbal, K., Liu, F. and Gong, C.X. 2014. Intracerebroventricular streptozotocin exacerbates Alzheimer-like changes of 3xTg-AD mice. Mol. Neurobiol. 49: 547-562. [Medline] [CrossRef]

7. Cumming, P., Danielsen, E.H., Vafaee, M., Falborg, L., Steffensen, E., Sørensen, J.C., Gillings, N., Bender, D., Marthi, 
K., Andersen, F., Munk, O., Smith, D., Møller, A. and Gjedde, A. 2001. Normalization of markers for dopamine innervation in striatum of MPTP-lesioned miniature pigs with intrastriatal grafts. Acta Neurol. Scand. 103: 309-315. [Medline] [CrossRef]

8. Dall, A.M., Danielsen, E.H., Sørensen, J.C., Andersen, F., Møller, A., Zimmer, J., Gjedde, A.H., Cumming, P., Danish Neuronal Xenografting Group. 2002. Quantitative [18F]fluorodopa/PET and histology of fetal mesencephalic dopaminergic grafts to the striatum of MPTP-poisoned minipigs. Cell Transplant. 11: 733-746. [Medline] [CrossRef]

9. Danielsen, E.H., Cumming, P., Andersen, F., Bender, D., Brevig, T., Falborg, L., Gee, A., Gillings, N.M., Hansen, S.B., Hermansen, F., Johansen, J., Johansen, T.E., Dahl-Jørgensen, A., Jørgensen, H.A., Meyer, M., Munk, O., Pedersen, E.B., Poulsen, P.H., Rodell, A.B., Sakoh, M., Simonsen, C.Z., Smith, D.F., Sørensen, J.C., Ostergård, L., Zimmer, J., Gjedde, A. and Møller, A. 2000. The DaNeX study of embryonic mesencephalic, dopaminergic tissue grafted to a minipig model of Parkinson's disease: preliminary findings of effect of MPTP poisoning on striatal dopaminergic markers. Cell Transplant. 9: 247-259. [Medline] [CrossRef]

10. Donald, R.D., Healy, S.D., Lawrence, A.B. and Rutherford, K.M. 2011. Emotionality in growing pigs: is the open field a valid test? Physiol. Behav. 104: 906-913. [Medline] [CrossRef]

11. Emborg, M.E. 2007. Nonhuman primate models of Parkinson's disease. ILAR J. 48: 339-355. [Medline] [CrossRef]

12. Goodman, S. and Check, E. 2002. The great primate debate. Nature 417: 684-687. [Medline] [CrossRef]

13. Kornum, B.R. and Knudsen, G.M. 2011. Cognitive testing of pigs (Sus scrofa) in translational biobehavioral research. Neurosci. Biobehav. Rev. 35: 437-451. [Medline] [CrossRef]

14. Langston, J.W., Ballard, P., Tetrud, J.W. and Irwin, I. 1983. Chronic Parkinsonism in humans due to a product of meperidine-analog synthesis. Science 219: 979-980. [Medline] [CrossRef]

15. Langston, J.W., Irwin, I., Langston, E.B. and Forno, L.S. 1984. 1-Methyl-4-phenylpyridinium ion (MPP+): identification of a metabolite of MPTP, a toxin selective to the substantia nigra. Neurosci. Lett. 48: 87-92. [Medline] [CrossRef]

16. Langston, J.W., Irwin, I., Langston, E.B. and Forno, L.S. 1984. Pargyline prevents MPTP-induced parkinsonism in primates. Science 225: 1480-1482. [Medline] [CrossRef]

17. Lind, N.M., Moustgaard, A., Jelsing, J., Vajta, G., Cumming, P. and Hansen, A.K. 2007. The use of pigs in neuroscience: modeling brain disorders. Neurosci. Biobehav. Rev. 31: 728751. [Medline] [CrossRef]

18. Lind, N.M., Vinther, M., Hemmingsen, R.P. and Hansen, A.K. 2005. Validation of a digital video tracking system for recording pig locomotor behaviour. J. Neurosci. Methods 143: 123-132. [Medline] [CrossRef]

19. Mikkelsen, M., Møller, A., Jensen, L.H., Pedersen, A., Harajehi, J.B. and Pakkenberg, H. 1999. MPTP-induced Parkinsonism in minipigs: A behavioral, biochemical, and histological study. Neurotoxicol. Teratol. 21: 169-175. [Medline] [CrossRef]

20. Mitra, N., Mohanakumar, K.P. and Ganguly, D.K. 1994. Resistance of golden hamster to 1-methyl-4-phenyl-1,2,3,6- tetrahydropyridine: relationship with low levels of regional monoamine oxidase B. J. Neurochem. 62: 1906-1912. [Medline] [CrossRef]

21. Moon, J.H., Kim, J.H., Im, H.J., Lee, D.S., Park, E.J., Song, K., Oh, H.J., Hyun, S.B., Kang, S.C., Kim, H., Moon, H.E., Park, H.W., Lee, H.J., Kim, E.J., Kim, S., Lee, B.C. and Paek, S.H. 2014. Proposed Motor Scoring System in a Porcine Model of Parkinson's Disease induced by Chronic Subcutaneous Injection of MPTP. Exp. Neurobiol. 23: 258-265. [Medline] [CrossRef]

22. Mounayar, S., Boulet, S., Tandé, D., Jan, C., Pessiglione, M., Hirsch, E.C., Féger, J., Savasta, M., François, C. and Tremblay, L. 2007. A new model to study compensatory mechanisms in MPTP-treated monkeys exhibiting recovery. Brain 130: 2898-2914. [Medline] [CrossRef]

23. Petzinger, G.M., Fisher, B., Hogg, E., Abernathy, A., Arevalo, P., Nixon, K. and Jakowec, M.W. 2006. Behavioral motor recovery in the 1-methyl-4-phenyl-1,2,3,6-tetrahydropyridine-lesioned squirrel monkey (Saimiri sciureus): changes in striatal dopamine and expression of tyrosine hydroxylase and dopamine transporter proteins. J. Neurosci. Res. 83: 332-347. [Medline] [CrossRef]

24. Potts, L.F., Wu, H., Singh, A., Marcilla, I., Luquin, M.R. and Papa, S.M. 2014. Modeling Parkinson's disease in monkeys for translational studies, a critical analysis. Exp. Neurol. 256: 133-143. [Medline] [CrossRef]

25. Przedborski, S., Jackson-Lewis, V., Naini, A.B., Jakowec, M., Petzinger, G., Miller, R. and Akram, M. 2001. The parkinsonian toxin 1-methyl-4-phenyl-1,2,3,6-tetrahydropyridine (MPTP): a technical review of its utility and safety. J. Neurochem. 76: 1265-1274. [Medline] [CrossRef]

26. Sanchis-Segura, C., Lopez-Atalaya, J.P. and Barco, A. 2009. Selective boosting of transcriptional and behavioral responses to drugs of abuse by histone deacetylase inhibition. Neuropsychopharmacology 34: 2642-2654. [Medline] [CrossRef]

27. Seo, J., Lee, Y., Kim, B.S., Park, J., Yang, S., Yoon, H.J., Yoo, J., Park, H.S., Hong, J.J., Koo, B.S., Baek, S.H., Jeon, C.Y., Huh, J.W., Kim, Y.H., Park, S.J., Won, J., Ahn, Y.J., Kim, K., Jeong, K.J., Kang, P., Lee, D.S., Lim, S.M., Jin, Y.B. and Lee, S.R. 2019. A non-human primate model for stable chronic Parkinson's disease induced by MPTP administration based on individual behavioral quantification. J. Neurosci. Methods 311: 277-287. [Medline] [CrossRef]

28. Smeyne, R.J. and Jackson-Lewis, V. 2005. The MPTP model of Parkinson's disease. Brain Res. Mol. Brain Res. 134: 5766. [Medline] [CrossRef]

29. Song, B.S., Jeong, P.S., Lee, J.H., Lee, M.H., Yang, H.J., Choi, S.A., Lee, H.Y., Yoon, S.B., Park, Y.H., Jeong, K.J., Kim, Y.H., Jin, Y.B., Kim, J.S., Sim, B.W., Huh, J.W., Lee, S.R., Koo, D.B., Chang, K.T. and Kim, S.U. 2018. The effects of kinase modulation on in vitro maturation according to different cumulus-oocyte complex morphologies. PLoS One 13: e0205495. [Medline] [CrossRef]

30. Willens, S., Cox, D.M., Braue, E.H., Myers, T.M. and Wegner, M.D. 2014. Novel technique for retroperitoneal implantation of telemetry transmitters for physiologic monitoring in Göttingen minipigs (Sus scrofa domesticus). Comp. Med. 64: 464-470. [Medline] 